\title{
Conservation of allelic multiplicity and genotypic frequency by pooling wild populations of perennial ryegrass
}

\author{
FRANCOIS BALFOURIER*, GILLES CHARMET \& CATHERINE GRAND-RAVEL \\ INRA, Plant Breeding Station, 63039, Clermont-Ferrand, France
}

\begin{abstract}
Three experimental breeding populations, created by pooling four to five natural populations of perennial ryegrass, were used to indicate the effect of sampling and pooling on the retention of genetic variation. Conservation of allelic multiplicity and genotypic frequencies was observed using allelic frequencies measured on six isozyme markers. We observed that by bulking four or five natural populations, represented respectively by 25 or 20 plants, in a large polycross design, the allelic and genotypic frequencies of the original mother-plants were conserved. There was no loss of rare alleles $(0.01<p<0.10)$ in the three experimental populations compared with the original natural populations. Only very rare alleles $(p<0.01)$ were reduced in frequency or lost. The value of such a bulking approach is discussed and presented as a possible alternative to the core collection approach to the management and use of genetic resources of perennial ryegrass.
\end{abstract}

Keywords: allelic frequency, core collection, gene conservation, isozyme markers, Lolium perenne, population structure.

\section{Introduction}

The maintenance of a large collection of forage plants with only a limited number of seeds leads to serious problems (see review by Bray, 1983). The concept of the core collection, developed by Frankel (1984), can be an effective way to manage and conserve genetic variation. However, although the constitution of a core collection can improve the management of genetic resources, it may not always provide genetic variability for rapid use in plant breeding programmes.

In the case of a wild cross-pollinated forage species such as perennial ryegrass (Lolium perenne L.), genetic variability remains very scattered between and within the populations constituting the core collection (Charmet et al., 1994). Therefore, if the aim is to use genetic resources directly in plant breeding programmes, pooling populations may be an alternative way of providing adapted germplasm for plant breeders. However, it is important to consider the effects of sampling and bulking on the genetic constitution of pooled populations.

In this paper, we will consider the forage grass species, L. perenne which is widespread in temperate Europe. Many modern varieties of $L$. perenne have been bred for high production of dry matter under high

${ }^{*}$ Correspondence. levels of nitrogen. However, because of over-production of livestock products within the EC and ecological concerns over intensive agriculture, new varieties are being bred for better adaptation to reduced inputs of fertilizers and herbicides or for sowing on disturbed areas (e.g. motorway verges or ski slopes).

Here, our aim is to determine the most effective way of pooling a finite number of representative plants taken from wild populations, supposed to be of infinite or very large size, in order to create breeding populations which could be useful for achieving new breeding objectives and at the same time minimize loss of alleles.

In the present study we will consider three experimental populations, constituted by pooling four or five natural populations, in order to describe changes in genetic variation due to sampling and the formation of the breeding populations. Conservation of allelic and genotypic frequencies will be studied using six isozyme markers.

\section{Materials and methods}

A sample of 550 wild populations of perennial ryegrass was collected as seeds from all over France in 1983-84. This large collection has been evaluated and described (Charmet et al., 1990; Balfourier \& Charmet 1991). Several multivariate analyses have been per- 
these 550 populations, followed by various clustering methods. This permitted wild populations to be grouped according to their agronomic similarity, as well as their ecological and geographical proximity (Balfourier \& Charmet, 1994; Charmet et al., 1994).

For the present study, 14 wild populations were chosen to constitute three experimental populations. Each of these populations was collected as seeds from at least 50 plants taken from an ecologically homogeneous area of $100-1000 \mathrm{~m}^{2}$. This was considered to yield a sample of seeds representative of the original panmictic population (Tyler et al., 1984). Table 1 gives the origins and accession numbers of these 14 populations. As described by Balfourier \& Charmet (1994), the populations were chosen according to their original habitats and their groupings for agronomic similarity (agronomic cluster).

The first five populations, originating from roadside habitats, were sampled from agronomic cluster no. 9 and were used to form the experimental population named 'BR9'. The next five populations originated from pasture habitats, also from agronomic cluster no. 9, and constituted experimental population 'PP9'. Finally, four populations collected from pathway habitats and sampled from agronomic cluster no. 2 formed experimental population ' $\mathrm{CH} 2$ '.

In autumn 1990, 20 plants were chosen at random from each of the five original populations constituting BR9. These were planted in an isolated field, in order to allow all 100 plants to intercross panmictically, as perennial ryegrass is a self-incompatible outbreeder. This design was repeated to polycross the five original populations of PP9. However, as breeding population

Table 1 Accession numbers and origins of the 14 natural populations of perennial ryegrass

\begin{tabular}{|c|c|c|c|}
\hline Population & $\begin{array}{l}\text { Accession } \\
\text { number }\end{array}$ & $\begin{array}{l}\text { Region } \\
\text { of origin }\end{array}$ & $\begin{array}{c}\text { Original } \\
\text { habitat }\end{array}$ \\
\hline BR9-1 & 10875 & Franche-Comte & Roadside \\
\hline BR9-2 & 11154 & Centre & Roadside \\
\hline BR9-3 & 11163 & Centre & Roadside \\
\hline BR9-4 & 11178 & Centre & Roadside \\
\hline BR9-5 & 11274 & Centre & Roadside \\
\hline PP9-1 & 10652 & Lorraine & Meadow \\
\hline PP9-2 & 10656 & Lorraine & Meadow \\
\hline PP9-3 & 10674 & Lorraine & Meadow \\
\hline PP9-4 & 11279 & Auvergne & Meadow \\
\hline PP9-5 & 11280 & Auvergne & Meadow \\
\hline $\mathrm{CH} 2-1$ & 10604 & Champagne-Ardennes & Pathway \\
\hline $\mathrm{CH} 2-2$ & 10607 & Champagne-Ardennes & Pathway \\
\hline $\mathrm{CH} 2-3$ & 10608 & Champagne-Ardennes & Pathway \\
\hline $\mathrm{CH} 2-4$ & 10616 & Champagne-Ardennes & Pathway \\
\hline
\end{tabular}

$\mathrm{CH} 2$ consisted of only four original populations, 25 plants per population were chosen randomly to keep the total number of founders to 100 .

In summer 1991, seeds produced by outcrossing between the original populations of the three experimental populations were harvested separately from each surviving mother-plant.

The conservation of allelic and genotypic frequencies was assessed using starch gel electrophoresis. Six enzyme systems were examined on slices of a single lithium-borate starch gel: phosphoglucoisomerase (PGI, E.C. 5.3.1.9), acid phosphatase (ACP, E.C. 3.1.3.2), glutamate-oxaloacetate-transaminase (GOT, E.C. 2.6.1.1), superoxide-dismutase (SOD, E.C. 1:15.1.1), peroxidase (PRX, E.C. 1.11.1.7) and isocitrate-dehydrogenase (IDH, E.C. 1.1.1.42). Enzyme extractions, electrophoresis and enzyme assays were carried out according to the procedures of Hayward \& McAdam (1977), and of Pollans \& Allard (1985) for PRX.

Starch gel electrophoresis analysis was carried out at three stages of the breeding experiment: first, samples of 4-6 weeks old plants were taken from each of the 14 original populations and analysed to obtain allelic frequencies and test for Hardy-Weinberg equilibrium; most samples were of 110-150 plants. Secondly, all mother-plants used in the three polycrosses and still growing in the field in Spring 1991, were analysed for the same six isozyme markers. Finally, seeds harvested in Summer 1991 from these mother-plants were used to estimate allelic and genotypic frequencies for the three experimental populations. Two seeds per mother-plant were grown and analysed after 4-6 weeks.

The BIOsYs-1 program (Swofford \& Selander, 1981) was used to test Hardy-Weinberg expectations and to compute Wright's $F$-statistics. In order to calculate expected genotypic frequencies for the three experimental populations, we considered perennial ryegrass to be a completely outcrossing species (Cornish et al., 1979).

\section{Results}

\section{Preliminary remarks}

Each of the six enzyme systems revealed one readable and polymorphic isozyme locus: Pgi-2, Acp-2, Got-3, Sod-1, Prx-1 and Idh-1; other loci were observed for PGI, ACP and GOT, but were not used for the present study because of uncertainty in banding pattern interpretation or lack of polymorphism. Allelic frequencies for the six loci, observed in the five natural populations BR9-1, BR9-2, BR9-3, BR9-4 and BR9-5, and also in 
experimental population BR9, are shown in Table 2; in the same way Tables 3 and 4, respectively, show the results for $\mathrm{PP} 9$ and $\mathrm{CH} 2$.

For each natural population, allelic frequencies were calculated in two ways: ' $n$ ' seedlings were used to estimate allelic frequencies of the original populations and the ' $m$ ' mother-plants were also used to calculate allelic frequencies in the sample of plants actually used in the polycross.

The number of seedlings, $n$, mostly ranged from 110 to 150 per population, except for locus $\operatorname{Pr} x-1$ where some difficulties in banding pattern interpretation led us to consider fewer plants. For the mother-plants, polycrosses were made using $5 \times 20$ (BR9 and PP9) or $4 \times 25(\mathrm{CH} 2)$ mother-plants. However, as some of these mother-plants died during winter 1990-91, it was only the ' $m$ ' surviving mother-plants (i.e. those which had contributed to pollen and seed production in the polycrosses) which were used to calculate these new allelic frequencies ( $m$ ranging from 16 to 25).

For each of the experimental populations BR9, PP9 and $\mathrm{CH} 2$, three types of allelic frequencies are shown in Tables 2-4: (i) expected frequencies, which were calculated using allelic frequencies of the original populations (column: expected 1), (ii) expected frequencies, predicted by using the exact frequencies of the surviving mother-plants (column: expected 2), (iii) the observed frequencies (column: observed), estimated from 165 to 190 plants per experimental population (two seeds per mother-plant).

\section{Allelic polymorphism}

For Pgi-2, five alleles were found and denoted $a$ to $e$, from the most anodal to the most cathodal. No rare allele faster than $a$ was observed. Alleles $a$ and $b$ were very common; $c$ and $d$ were observed in some populations as rare alleles $(p<0.10)$, while allele $e$ was only noted in one population (BR9-4) with a very low frequency (very rare allele: $p=0.007$ ).

Only four active alleles were recorded for $A c p-2$ and named $a$ to $d$. Alleles $c$ and $d$ were quite rare. In addition, two extremely rare alleles were recorded in one population each: $a+(p=0.004)$ faster than $a$ was observed in population BR9-3 and $e(p=0.004)$ slower than $d$ in population PP9-1.

On analysis of Got-3, four alleles were observed and denoted $a$ to $d$. Allele $b$ was very common whereas $a$ and $d$ were quite rare.

Only two alleles were revealed for Sod-1 which is not a very polymorphic locus: rare allele $a$ was only observed in a few populations. Similarly, two alleles named $b$ and $c$ were observed for $\operatorname{Prx}-1$, the rarer being $b$.
Lastly, four alleles were revealed for $\operatorname{Id} h-1(a, b, c, d)$ but only three banding patterns were scorable on lithium-borate starch gel where the $b$ and $c$ alleles overlap. Alleles $a$ and $d$ were observed as rare alleles in some populations.

We observed that common alleles $(p>0.10)$ were correctly represented in the surviving 16-25 motherplants when sampling 20-25 plants per population (for example alleles $a$ and $b$ for Pgi-2 and Acp-2, alleles $b$ and $c$ for Got-3, b for Sod-1, b plus $c$ for Idh-1 or $c$ for $\operatorname{Pr} x-1)$. In contrast, alleles whose frequencies were $<0.03$ in the original populations were mostly lost when sampling only 20-25 plants per population. Thus, rare alleles Pgi-2d, $A c p-2 d$ and Got-3d were often lost whereas very rare alleles, for example $A c p-2 a+$ in BR9-3 and Pgi-2e in BR9-4, were nearly always lost. However, when rare alleles were retained in the sample of 20-25 plants, their observed frequency increased because of the relatively low sample size (e.g. allele Got-3a for BR9-1, BR9-4, BR9-5 or allele $I d h-1 d$ for BR9-4, PP9-3 or PP9-5).

Comparisons between allelic frequencies calculated from the original population samples (mostly 110-150 plants) and those from the 16-25 living mother-plants were in agreement with the expectations of Bray (1983). If the frequency of allele $A$ is $p$ and that of $a$ is $q$, then the probability of losing allele $a$, taking $n$ seeds, is $\left(p^{2}+F p q\right)^{\text {n }}$, where $F$ is the average inbreeding coefficient. The value of this coefficient has been estimated at 0.04 by Charmet et al. (1993) based on 60 populations of $L$. perenne, which is the same value as that reported by Hayward \& McAdam (1977).

Thus, when we take $16-25$ seeds, it is likely, as observed, that some rare alleles whose frequency $q$ is $<0.03$ will be lost, as for $q=0.03$, the probability of loss ranges from 0.38 (for 16 plants) to 0.23 (for 25 plants). However, the probability of saving at least one copy of each very rare allele is $1-(0.38)^{5}=0.992$ when we use five original populations (if this allele has the same frequency, $q=0.03$, in all five populations) and $1-(0.23)^{4}=0.997$ for four original populations.

Results concerning experimental populations BR9, PP9 and $\mathrm{CH} 2$ are also given in Table 2-4, respectively. The allelic frequencies among the mother-plants of each polycross permitted prediction of expected frequencies (column 2) for each experimental population. All $\chi^{2}$ tests, calculated from observed and expected frequencies (column 2), were not significant, whatever the number of plants sampled in each population: $4 \times 25$ or $5 \times 20$. Also, except for the Acp-2 locus of BR9, all $\chi^{2}$ tests between observed and expected frequencies (column 1) (i.e. calculated with the original population allelic frequencies) were not significant. Only very rare alleles $(p<0.01)$ were lost (e.g. alleles Pgi-2e, Acp-2a+ and Got-3d in BR9, 


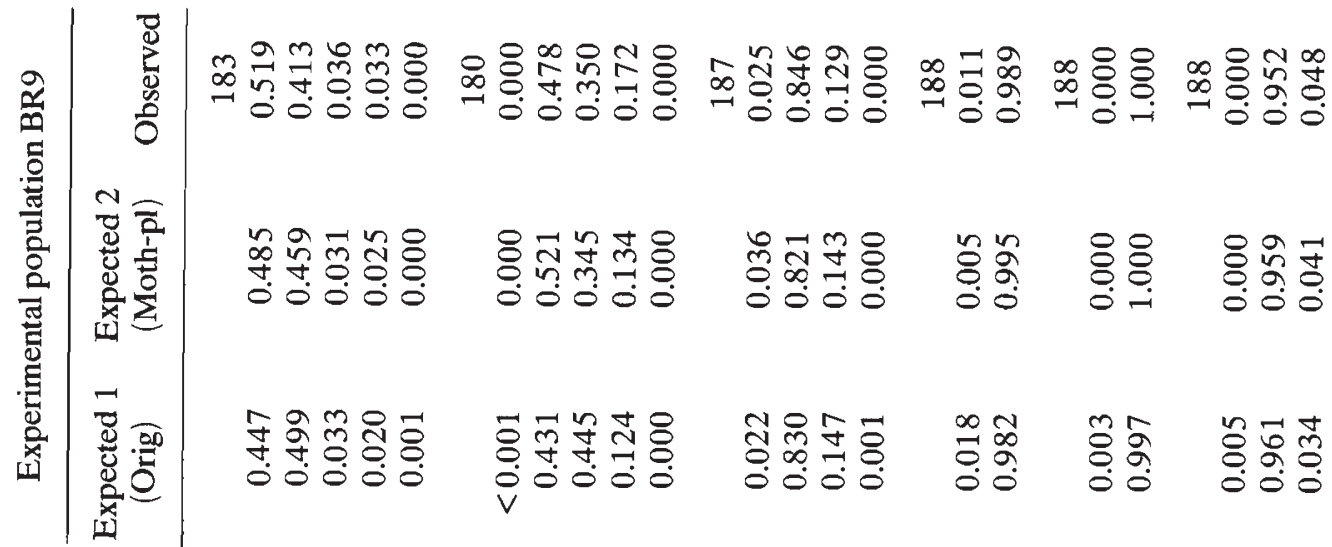
盗| 产

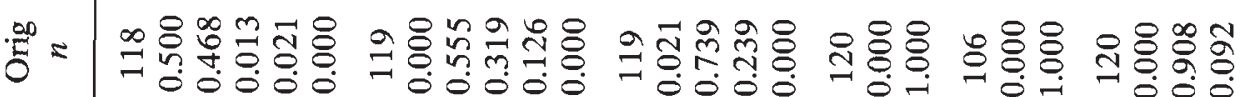

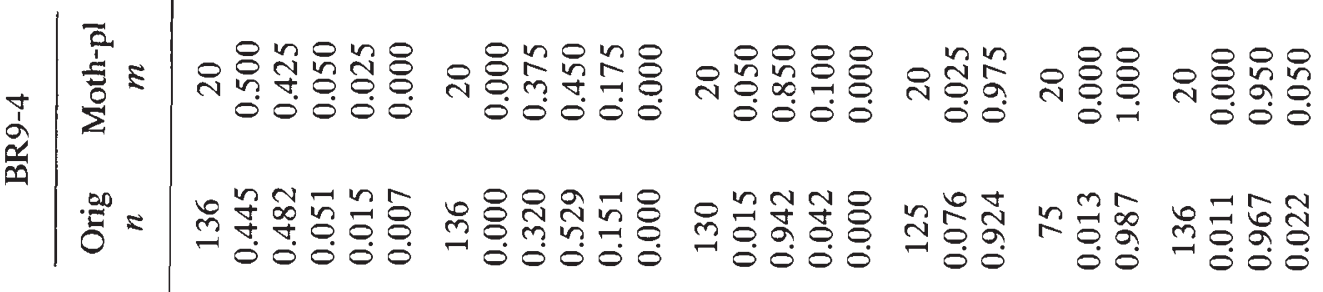

葛

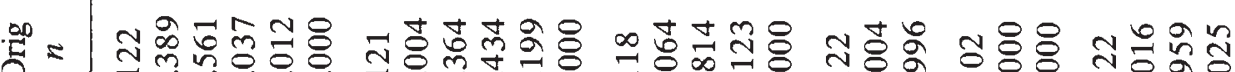

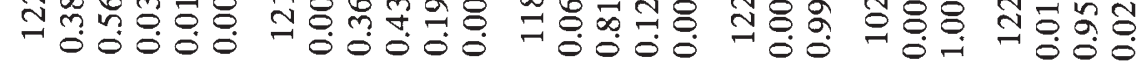

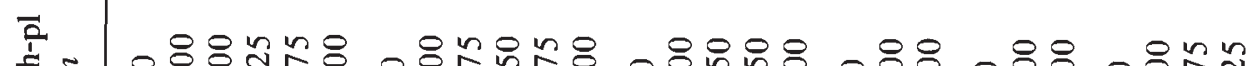

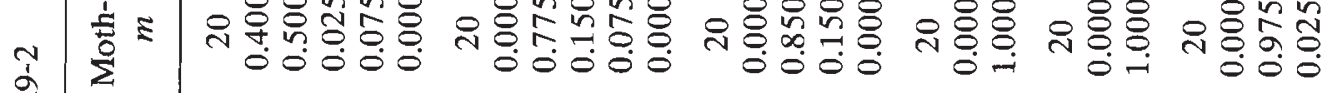
商

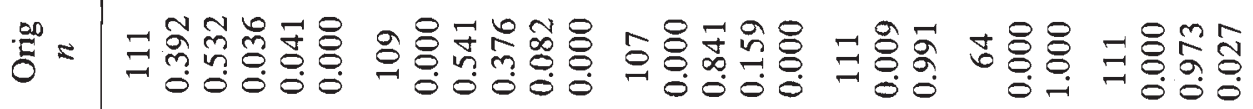

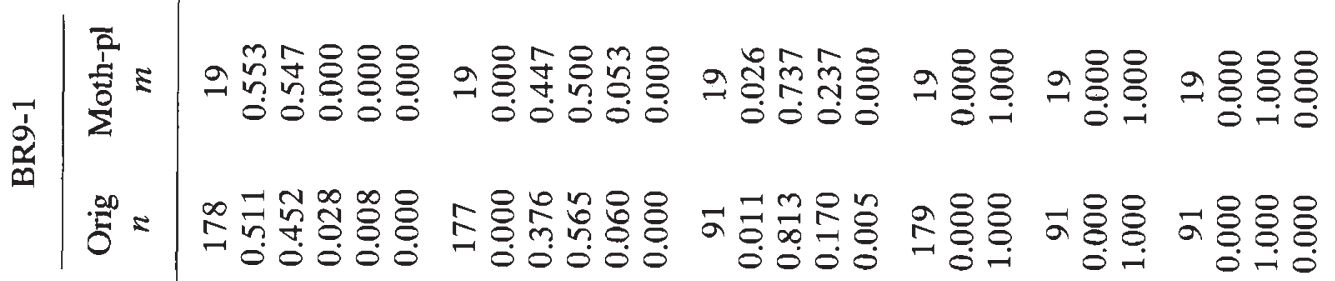
o 000 $+00+$ . 000 0000000

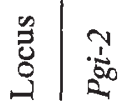

ֻे

$\frac{0}{5}$

సँ

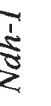




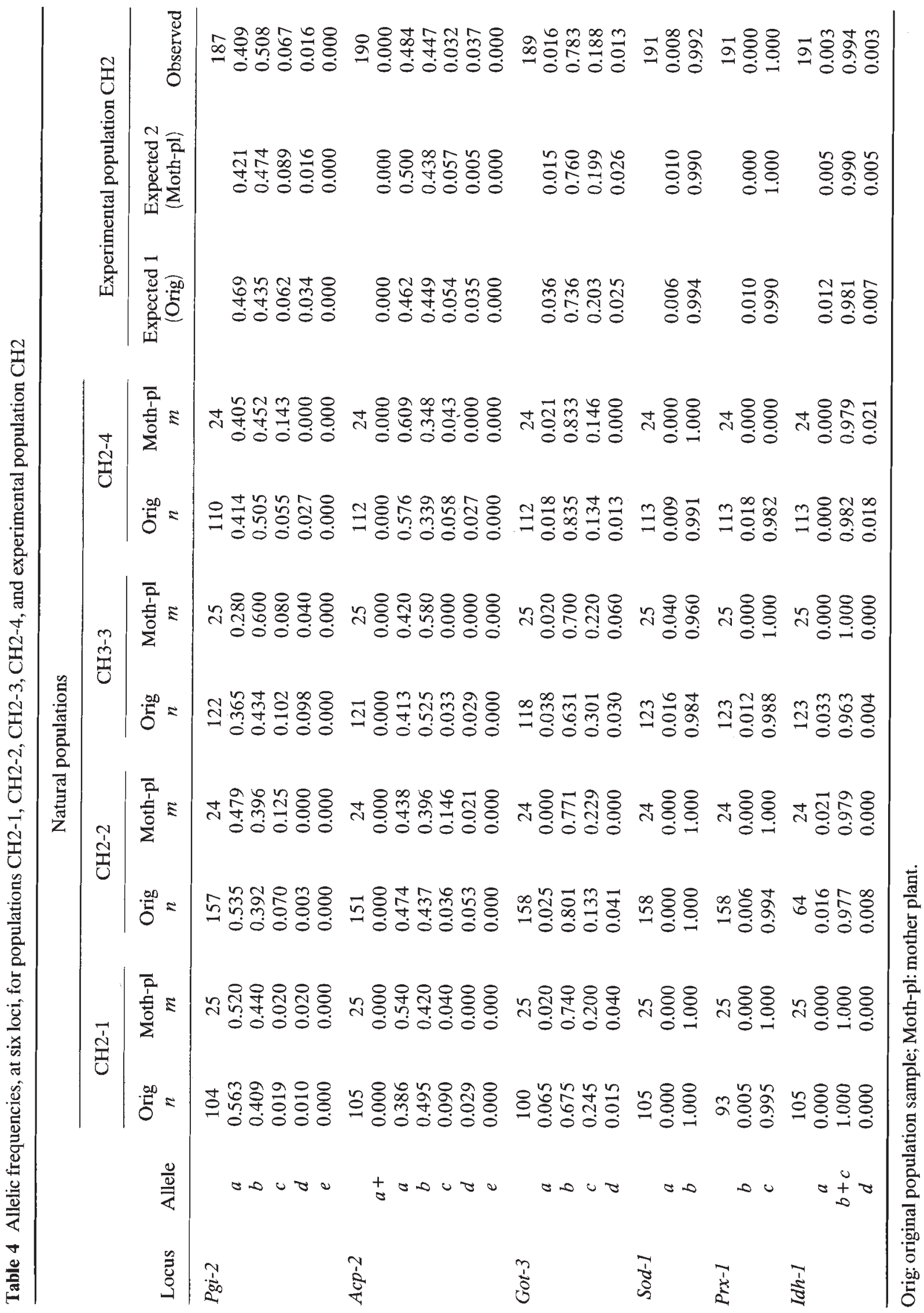


$P r x-1 b$ in BR9 and $\mathrm{CH} 2, I d h-1 a$ in PP9) and this did not affect the value of the $\chi^{2}$ statistics.

\section{Genetic variability}

Table 5 summarizes genetic variability for the six loci in the 14 natural populations and the three experimental populations. Natural populations show mean numbers of alleles per locus ranging from 2.5 to 3.2 and high percentages of polymorphic loci. Furthermore, comparisons between the mean heterozygosities per locus by direct counting and the mean heterozygosities expected assuming Hardy-Weinberg distributions (Nei, 1978) showed no significant deviations (standard errors are given in brackets). Furthermore, comparisons between the mean heterozygosities per locus by direct counting and the mean heterozygosities expected assuming Hardy-Weinberg distributions (Nei, 1978) showed no significant deviations (standard errors are given in brackets). Nevertheless, for all 14 populations the expected heterozygosity was greater than that observed and, therefore, there may be a slight deficiency of heterozygotes in the original populations.

We observed decreases in the number of alleles and the percentage of polymorphic loci in mother-plants compared with the original natural populations. However, the experimental populations contained mean numbers of alleles per locus similar to the natural populations. Values for heterozygosity indicated that satisfactory panmictic conditions had occurred in all polycrosses (standard errors are given in brackets).

Table 6 shows Wright's $F_{\text {IS }}$ statistics for four loci in the 14 natural populations; 95 per cent confidence intervals, calculated by the jackknife method (Efron, 1982), are given in brackets. Results are not given for loci Sod-1 and Prx-1 because the lack of heterozygosity may arise from sampling errors and the uncertainty of rare allele detection (Sod-1 $a$ and Prx-1b). The genotypic distributions were found on average to be in Hardy-Weinberg proportions at the Pgi-2, Got-3 and Idh-1 loci $\left(F_{\text {IS }}<0.08\right)$. In contrast, $F_{\text {IS }}$ values were larger for $A c p-2$.

Table 7 gives expected and observed sizes of the different classes of genotypes for the Pgi-2, Acp-2 and Got 3 loci in the three experimental populations; $\chi^{2}$ tests indicate no significant differences, with the exception of the $A c p-2$ locus in experimental population BR9.

\section{Discussion}

Polymorphism within populations of Lolium perenne

Allelic frequencies, mean numbers of alleles and mean heterozygosities were consistent with the results found for the same species by different authors (Hayward \& McAdam, 1977; Ostergaard et al., 1985; Lallemand et al., 1991). In contrast, mean numbers of alleles and percentages of polymorphic loci were greater for $L$. perenne than for another forage species Festuca ovina (Weibull et al., 1986). The $F_{\text {IS }}$ values indicate very low levels of inbreeding, probably caused by mating between related plants. The higher values for $A c p-2$ in each population might result from the presence of a silent allele (Ostergaard et al., 1985) or from misinterpretation when using lithium-borate gels which did not allow discrimination between the $b$ and $c$ alleles.

These different results indicate that on average the 14 natural populations were in panmictic equilibrium. We might be surprised by the similarity of the populations in their allelic frequencies despite the fact that they have been allocated to different groups by ecogeographical origin and cluster analysis on agronomic traits. In fact, for an allogamous species like $L$. perenne, there is little differentiation between wild populations, most of the differentiation being within populations (Charmet et al., 1993). A practical consequence of this low differentiation between populations could be that a small number of populations would be sufficient to preserve most of the genetic diversity. However, this result only applies to isozyme variation and cannot, at present, be generalized to other agronomic traits which are polygenic and subjected to various selection pressures. Work is progressing to compare the agronomic value of natural populations with the experimental populations originated by pooling.

\section{Conservation of polymorphisms after sampling and bulking populations}

Many studies have been carried out concerning the loss of alleles as a result of random drift or founder effect (bottleneck effect) caused by a reduction of population size. However, most are theoretical studies, such as Kimura \& Crow (1964), Nei et al. (1975), Sirkkomaa (1983) or Maruyama \& Fuerst (1985). Some experimental studies have been made mainly on animal species, such as Drosophila (Wright \& Kerr, 1954; Buri, 1956), elephant seal (Bonnell \& Selander, 1974) and more recently a snail (Johnson, 1988) and pacific salmon (Waples, 1990) in which base populations are generally small.

In comparing wild populations of barley and maize with modern cultivars, Allard (1992) has suggested that it is the most frequent alleles in the wild populations which are the most potentially useful for breeding and are, therefore, preserved in modern varieties.

As stated previously, each of the 14 original populations was collected as seeds from at least 50 plants in a restricted area. According to Yonezawa (1985), we can 
Table 5 Summary of genetic variability calculated on the natural and the experimental populations (standard errors are given in brackets)

\begin{tabular}{|c|c|c|c|c|c|c|c|c|}
\hline \multirow[b]{3}{*}{ Populations } & \multicolumn{4}{|c|}{ Natural populations } & \multicolumn{4}{|c|}{ Mother-plants } \\
\hline & \multirow{2}{*}{$\begin{array}{l}\text { Mean no. } \\
\text { of alleles } \\
\text { per locus }\end{array}$} & \multirow{2}{*}{$\begin{array}{c}\text { Percentage } \\
\text { of loci } \\
\text { polymorphic }\end{array}$} & \multicolumn{2}{|c|}{ Mean heterozygosity } & \multirow{2}{*}{$\begin{array}{l}\text { Mean no. } \\
\text { of alleles } \\
\text { per locus }\end{array}$} & \multirow{2}{*}{$\begin{array}{l}\text { Percentage } \\
\text { of loci } \\
\text { polymorphic }\end{array}$} & \multicolumn{2}{|c|}{ Mean heterozygosity } \\
\hline & & & $\left(H_{\mathrm{o}}\right)$ & $\left(H_{s}\right)$ & & & $\left(H_{0}\right)$ & $\left(H_{s}\right)$ \\
\hline BR9-1 & 2.5 & 50.0 & $\begin{array}{c}0.191 \\
(0.093)\end{array}$ & $\begin{array}{c}0.231 \\
(0.109)\end{array}$ & 1.8 & 50.0 & $\begin{array}{c}0.149 \\
(0.074)\end{array}$ & $\begin{array}{c}0.247 \\
(0.112)\end{array}$ \\
\hline BR9-2 & 2.5 & 83.3 & $\begin{array}{c}0.201 \\
(0.095)\end{array}$ & $\begin{array}{c}0.244 \\
(0.108)\end{array}$ & 2.2 & 66.7 & $\begin{array}{c}0.192 \\
(0.103)\end{array}$ & $\begin{array}{c}0.215 \\
(0.099)\end{array}$ \\
\hline BR9-3 & 3.0 & 83.3 & $\begin{array}{c}0.237 \\
(0.101)\end{array}$ & $\begin{array}{c}0.267 \\
(0.116)\end{array}$ & 2.2 & 66.7 & $\begin{array}{c}0.211 \\
(0.103)\end{array}$ & $\begin{array}{c}0.245 \\
(0.119)\end{array}$ \\
\hline BR9-4 & 3.2 & 100.0 & $\begin{array}{c}0.207 \\
(0.081)\end{array}$ & $\begin{array}{c}0.253 \\
(0.107)\end{array}$ & 2.5 & 83.3 & $\begin{array}{c}0.208 \\
(0.093)\end{array}$ & $\begin{array}{c}0.274 \\
(0.113)\end{array}$ \\
\hline BR9-5 & 2.5 & 66.7 & $\begin{array}{c}0.275 \\
(0.107)\end{array}$ & $\begin{array}{c}0.281 \\
(0.107)\end{array}$ & 2.2 & 66.7 & $\begin{array}{c}0.297 \\
(0.121)\end{array}$ & $\begin{array}{c}0.277 \\
(0.104)\end{array}$ \\
\hline PP9-1 & 3.0 & 83.3 & $\begin{array}{c}0.247 \\
(0.110)\end{array}$ & $\begin{array}{c}0.263 \\
(0.110)\end{array}$ & 2.5 & 66.7 & $\begin{array}{c}0.263 \\
(0.120)\end{array}$ & $\begin{array}{c}0.282 \\
(0.109)\end{array}$ \\
\hline PP9-2 & 2.7 & 83.3 & $\begin{array}{c}0.287 \\
(0.120)\end{array}$ & $\begin{array}{c}0.301 \\
(0.124)\end{array}$ & 2.0 & 50.0 & $\begin{array}{c}0.199 \\
(0.096)\end{array}$ & $\begin{array}{c}0.265 \\
(0.120)\end{array}$ \\
\hline PP9-3 & 2.5 & 83.3 & $\begin{array}{c}0.232 \\
(0.084)\end{array}$ & $\begin{array}{c}0.261 \\
(0.093)\end{array}$ & 2.0 & 66.7 & $\begin{array}{c}0.311 \\
(0.107)\end{array}$ & $\begin{array}{c}0.312 \\
(0.107)\end{array}$ \\
\hline PP9-4 & 2.8 & 100.0 & $\begin{array}{c}0.282 \\
(0.097)\end{array}$ & $\begin{array}{c}0.309 \\
(0.097)\end{array}$ & 2.2 & 83.3 & $\begin{array}{c}0.269 \\
(0.117)\end{array}$ & $\begin{array}{c}0.244 \\
(0.096)\end{array}$ \\
\hline PP9-5 & 3.0 & 100.0 & $\begin{array}{c}0.287 \\
(0.113)\end{array}$ & $\begin{array}{c}0.292 \\
(0.115)\end{array}$ & 2.3 & 83.3 & $\begin{array}{c}0.295 \\
(0.103)\end{array}$ & $\begin{array}{c}0.269 \\
(0.086)\end{array}$ \\
\hline $\mathrm{CH} 2-1$ & 2.7 & 66.7 & $\begin{array}{c}0.228 \\
(0.102)\end{array}$ & $\begin{array}{c}0.269 \\
(0.120)\end{array}$ & 2.3 & 50.0 & $\begin{array}{c}0.207 \\
(0.095)\end{array}$ & $\begin{array}{c}0.251 \\
(0.114)\end{array}$ \\
\hline $\mathrm{CH} 2-2$ & 3.0 & 83.3 & $\begin{array}{c}0.219 \\
(0.092)\end{array}$ & $\begin{array}{c}0.256 \\
(0.112)\end{array}$ & 2.2 & 66.7 & $\begin{array}{c}0.229 \\
(0.101)\end{array}$ & $\begin{array}{c}0.276 \\
(0.124)\end{array}$ \\
\hline $\mathrm{CH} 2-3$ & 3.2 & 100.0 & $\begin{array}{c}0.256 \\
(0.105)\end{array}$ & $\begin{array}{c}0.309 \\
(0.121)\end{array}$ & 2.3 & 66.7 & $\begin{array}{c}0.259 \\
(0.118)\end{array}$ & $\begin{array}{c}0.268 \\
(0.110)\end{array}$ \\
\hline $\mathrm{CH} 2-4$ & 3.0 & 100.0 & $\begin{array}{c}0.222 \\
(0.099)\end{array}$ & $\begin{array}{c}0.249 \\
(0.107)\end{array}$ & 2.2 & 66.7 & $\begin{array}{c}0.216 \\
(0.100)\end{array}$ & $\begin{array}{c}0.246 \\
(0.113)\end{array}$ \\
\hline \multirow{3}{*}{\multicolumn{3}{|c|}{ Experimental population }} & & BR9 & 2.7 & 83.3 & $\begin{array}{c}0.244 \\
(0.102)\end{array}$ & $\begin{array}{c}0.262 \\
(0.113)\end{array}$ \\
\hline & & & & PP9 & 3.2 & 100.0 & $\begin{array}{c}0.261 \\
(0.102)\end{array}$ & $\begin{array}{c}0.289 \\
(0.113)\end{array}$ \\
\hline & & & & $\mathrm{CH} 2$ & 3.2 & 100.0 & $\begin{array}{c}0.244 \\
(0.109)\end{array}$ & $\begin{array}{c}0.255 \\
(0.113)\end{array}$ \\
\hline
\end{tabular}

$H_{\mathrm{o}}$ : observed by direct counting; $H_{\mathrm{s}}$ : expected assuming Hardy-Weinberg distribution.

assume that this sampling technique is effective in collecting the majority of genetic variability in each population. By using mostly $110-150$ plants per natural population for the electrophoretic survey, we ensure, as reported by Gregorius (1980), that all alleles with frequency $>0.04$ are detected with a probability of 95 per cent. If we define an allele to be rare if it never occurs with frequency $>0.10$ (Brown, 1978), we can assume that rare alleles, with a frequency between 0.10 and 0.04 , are detected with a probability of 95 per cent. In our case, only the very rare alleles $(p<0.01)$ were lost in the experimental populations.

Our results indicate that the establishment of polycrosses, when using 16-25 mother-plants per population, can result in the loss of rare alleles. However, except for very rare alleles, such as $A c p-2 a+$ or Pgi-2e, the loss of an allele in some populations is compensated by a randomly increased frequency in other populations of the same group (BR9, PP9 or $\mathrm{CH} 2$ ) which produces a buffering effect (e.g. allele $I d h-1 d$ in 
Table 6 Wright's $F_{\text {IS }}$ statistics, for four loci, in the 14 natural populations

\begin{tabular}{lcrrrr}
\hline Population & $\begin{array}{c}\text { Mean sample size } \\
\text { per locus }\end{array}$ & Pgi-2 & Acp-2 & Got-3 & ldh-1 \\
\hline BR9-1 & 134.5 & 0.031 & 0.263 & 0.255 & $*$ \\
BR9-2 & 102.2 & -0.028 & 0.346 & 0.231 & -0.028 \\
BR9-3 & 117.8 & -0.002 & 0.235 & -0.010 & 0.277 \\
BR9-4 & 123.0 & 0.144 & 0.291 & -0.049 & 0.202 \\
BR9-5 & 117.0 & -0.083 & 0.048 & 0.065 & 0.099 \\
PP9-1 & 117.7 & -0.074 & 0.177 & 0.081 & -0.009 \\
PP9-2 & 116.3 & 0.104 & 0.181 & -0.166 & -0.031 \\
PP9-3 & 114.5 & 0.056 & 0.091 & 0.318 & -0.123 \\
PP9-4 & 124.3 & -0.092 & 0.161 & 0.098 & -0.021 \\
PP9-5 & 104.7 & -0.029 & 0.064 & 0.029 & $* 0.013$ \\
CH2-1 & 102.0 & 0.013 & 0.218 & 0.208 & -0.019 \\
CH2-2 & 141.0 & 0.117 & 0.259 & 0.010 & 0.196 \\
CH2-3 & 121.7 & 0.091 & 0.356 & 0.050 & -0.018 \\
CH2-4 & 112.2 & -0.067 & 0.353 & -0.004 & 0.041 \\
Weighted average & & 0.012 & 0.218 & 0.076 & $(-0.175-0.260)$ \\
& & $(-0.128-0.154)$ & $(0.034-0.400)$ & $(-0.154-0.314)$ & \\
\hline
\end{tabular}

*Absence of heterozygotes; 95 per cent confidence intervals are given in brackets.

PP9). This phenomenon is very well explained by Pollans \& Allard (1989) who showed that the variance of allelic frequencies increased when population size decreased.

Furthermore, our results showed that allelic loss occurs more rapidly than loss of genetic heterozygosity and, as reported by Maruyama \& Fuerst (1985), the deficit in allele number arises principally from a lack of those alleles that are expected to appear only once or twice in the sample.

In order to estimate accurately the probability of finding expected allelic frequencies for rare alleles in the three experimental populations, we analysed, as recommended by Gregorius (1980), 165-190 plants chosen by sampling two seeds per mother-plant. In this way we revealed very rare alleles, the expected frequencies of which were about 0.01 , and we observed a very good fit between expected and observed allelic frequencies. All $\chi^{2}$ tests (data not shown) were not significant.

We have seen that the number of founders involved in the PP9 experimental population, for instance, allowed the transfer of all alleles of a 5-allelic locus (e.g. Acp-2) to the next generation. These results are in agreement with those reported by Sirkkomaa (1983). In the same way, rare alleles, such as $P g i-2 c$ and $d$, Got$3 d$ Sod-Ia, Prx-1b, Idh-Ia and $d$ were well conserved by pooling populations with such a number of founders.
Also, genotypic frequencies were maintained after pooling populations; indeed, the observed and expected sizes of the different genotypic classes were similar, except for the $A c p-2$ locus in BR9 probably because of uncertainty and confusion in reading $b$ and $c$ alleles. On average, no linkage disequilibrium was apparent.

These results lead to the conclusion that bulking allows allelic and genotypic frequencies of original populations to be retained in most cases. Bearing in mind that the original populations had rather similar allelic compositions, no allelic loss was observed for alleles with $p>0.01$, and the original polymorphisms seemed to be conserved in the experimental populations. In fact, this study shows that the sampling effects (founder effect/bottleneck effect), which occur when sampling several single natural populations, can be offset by pooling these same populations. Thus, pooling accessions may have some advantages over taking a representative sample of single populations, which is the core collection concept. Although bulking could be an alternative way to manage and use genetic resources of perennial ryegrass, these results have been obtained by studying presumed neutral traits (isozymes). It would be judicious to check whether agronomic traits, expressed in the original populations, were retained in the bulked populations. Also, it would be important to study the influence of bulking on genetic parameters 


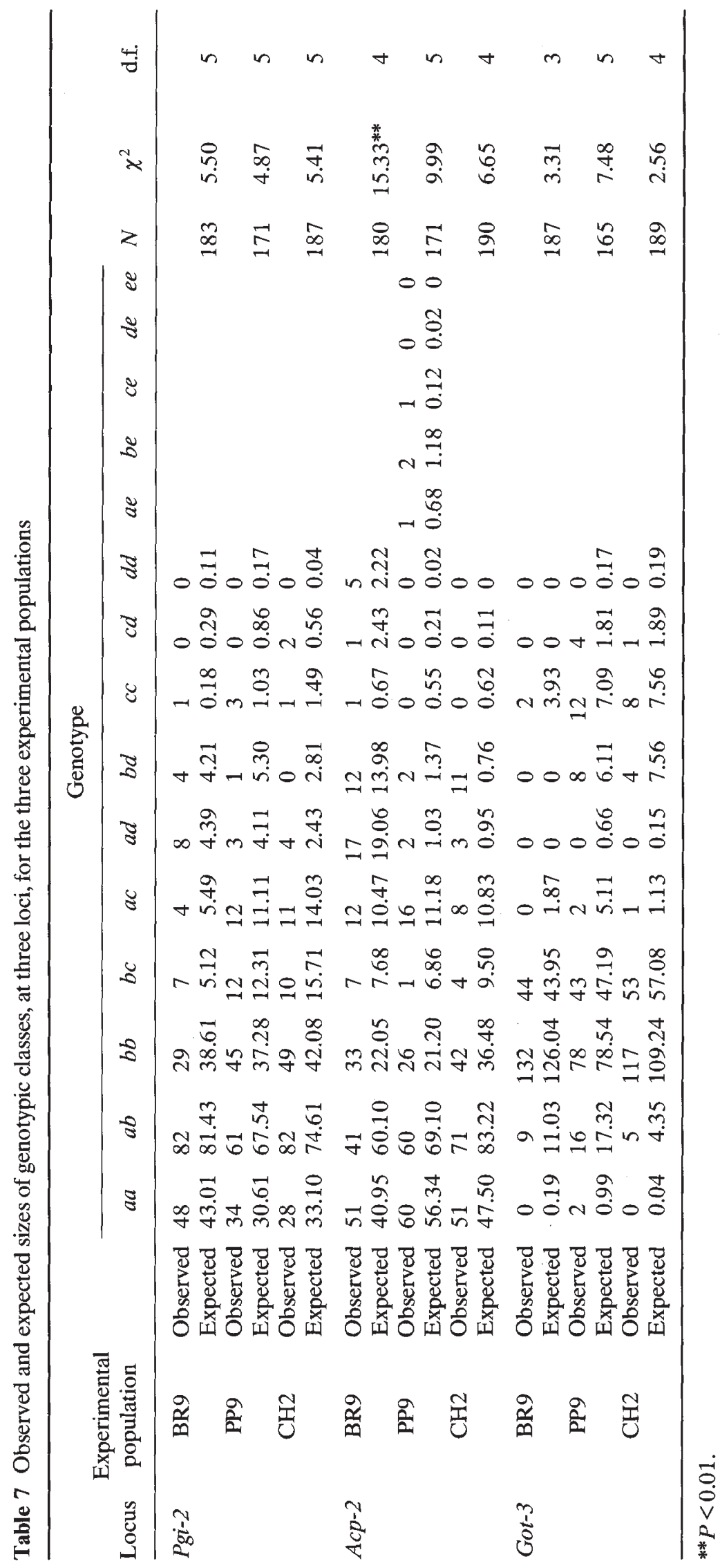


and on the expected response to selection. These problems are under investigation.

\section{Acknowledgement}

The authors thank Dr Marianne Lefort for constructive criticisms and helpful suggestions.

\section{References}

ALlARD, R. W. 1992. Reproductive systems and dynamic management of genetic resources. In: Datte, Y., Dumas, C. \& Gallais, A. (eds) Reproductive Biology and Plant Breeding, pp. 325-344. Springer, Berlin.

BALFOURIER, F. AND CHARMET, G. 1991. Relationships between agronomic characters and ecogeographical factors in the collection of French perennial ryegrass populations. Agronomie, 11, 645-657.

BALFOURIER, F. AND CHARMET, G. 1994. Etude méthodologique de la conservation de ressources génétiques de ray grass anglais par multiplication en pools de populations naturelles. Génét. Sél. Évol. (in press).

BONNELL, M. L. AND SELANDER, R. K. 1974. Elephant seals: genetic variation and near extinction. Science, 184, 908-909.

BRAY, R. A. 1983. Strategies for gene maintenance. In: McIvor J. G. and Bray R. A. (eds) Genetic Resources of Forage Plants, pp. 157-168. CSIRO, Melbourne.

BROWN, A. H. D. 1978. Isozymes, plant population genetic structure and genetic conservation. Theor. Appl. Genet., 52, 145-157.

BURI, P. 1956. Gene frequency in small populations of mutant Drosophila. Evolution, 10, 367-402.

CHARMET, G., BALFOURIER, F. AND BION, A. 1990. Agronomic evaluation of a collection of French perennial ryegrass populations: multivariate classification using genotype $\times$ environment interactions. Agronomie, 10, 807-823.

CHARMET, G., BALFOURIER, F. AND MONESTIEZ, P. 1994. Hierarchical clustering of perennial ryegrass populations with geographic contiguity constraint. Theor. Appl. Genet., 88, 42-48.

CHARMET, G., BALFOURIER, F. AND RAVEL, C. 1993. Isozyme polymorphism and geographic differentiation in a collection of French perennial ryegrass populations. Genet. Res. Crop Evol., 40, 77-89.

CORNISH, M. A., HAYWARD, M. D. AND LAWRENCE, M. J. 1979. Selfincompatibility in ryegrass. I. Genetic control in diploid Lolium perenne L. Heredity, 43, 95-106.

EFRON, B. 1982. The jacknife, the bootstrap and other resampling plans. CBMS-NSF Regional Conference Series in Applied Mathematics No. 38. Society for Industrial and Applied Mathematics, Philadelphia, PA.

FRANKEL, O. H. 1984. Genetic perspectives in germplasm conservation. In: Arber, W., Llimensee, K., Peacock, W. J. and Starlinger, P. (eds) Genetic Manipulation: Impact on Man and Society, pp. 161-170. Cambridge University Press, Cambridge.
GREGORIUS, H.-R. 1980. The probability of losing an allele when diploid genotypes are sampled. Biometrics, 36, 643-652.

HAYWARD, M. D. AND McADAM, N. J. 1977. Isozyme polymorphism as a measure of distinctiveness and stability in cultivars of Lolium perenne. Z. PflZücht., 79, 59-68.

JoHNSON, M. S. 1988. Founder effects and geographic variation in the land snail Theba pisana. Heredity, 61, 133-142.

KIMURA, M. AND CROW, J. F. 1964. The number of alleles that can be maintained in a finite population. Genetics, 49 , $725-738$.

LALLEMAND, J., MICHAUD, O. AND GRENECHE, M. 1991. Electrophoretical description of ryegrass varieties: a catalogue. Plant Varieties and Seeds, 4, 11-16.

MARUYAMA, T. AND FUERST, P. A. 1985. Population bottlenecks and nonequilibrium models in population genetics. II. Number of alleles in a small population that was formed by a recent bottleneck. Genetics, 111, 675-689.

NEI, M. 1978. Estimation of average heterozygosity and genetic distance from a small number of individuals. Genetics, 89, 583-590.

NEI, M., MARUYAMA, T. AND CHAKRABORTY, R. 1975. The bottleneck effect and genetic variability in populations. Evolution, 29, 1-10.

OSTERGAARD, H., NIELSEN, G. AND JOHANSEN, H. 1985. Genetic variation in cultivars of diploid ryegrass, Lolium perenne and L. multiflorum, at five enzyme systems. Theor. Appl. Genet., 69, 409-421.

POLLANS, N. O. AND ALLARD, R. W. 1985. Inheritance of electrophoretically detectable variants in ryegrass. J. Hered., 76, 61-62.

POLLANS, N. O. AND ALLARD, R. w. 1989. An experimental evaluation of the recovery potential of ryegrass populations from genetic stress resulting from restriction of population size. Evolution, 43, 1320-1324.

SIRKкомAA, s. 1983. Calculations on the decrease of genetic variation due to the founder effect. Hereditas, 99, 11-20.

SWOFFORD, D.L. AND SELANDER, R. B. 1981. BIOSYS-1: a Fortran Program for the comprehensive analysis of electrophoretic data in population genetics and systematics. J. Hered., 72, 281-283.

TYLER, B. F., CHORLTON, K. H. AND THOMAS, I. D. 1984. Characterisation of collected Lolium perenne populations. Report of the Welsh Plant Breeding Station 1983, Aberystwyth, UK, pp. 29-32.

WAPLES, R. S. 1990. Conservation genetics of Pacific salmon. II. Effective population size and the rate of loss of genetic variability. J. Hered., 81, 267-276.

WEIBULL, P., GHATNEKAR, L., FRYKMAN, I. AND BENGTSSON, B. O. 1986. Electrophoretic variation in Festuca ovina L. Agric. Hortique Genetica, 44, 25-37.

WRIGHT, S. AND KERR, W. E. 1954. Experimental studies of the distribution of gene frequencies in very small populations of Drosophila melanogaster. II. Bar. Evolution, 8, 225-240.

YONEZAWA, K. 1985. A definition of the optimal allocation of effort in conservation of plant genetic resources, with application to sample size determination for field collection. Euphytica, 34, 345-354. 